\title{
One Step Pyrolysis Preparation of Oriented 1.1.1 Gold Nanoplatelets Supported on Graphene and Six Orders of Magnitude Enhancement of the Resulting Catalytic Activity.
}

\author{
Ana Primo, ${ }^{[a]}$ Ivan Esteve-Adell, ${ }^{[a]}$ Simona N. Coman, ${ }^{[b]}$ Natalia Candu, ${ }^{[b]}$ Vasile I. Parvulescu ${ }^{[b]}$ and \\ Hermenegildo Garcia*[a]
}

\begin{abstract}
Pyrolysis of chitosan films containing $\mathrm{Au}^{3+}$ renders 1.1.1 oriented Au nanoplatelets ( $20 \mathrm{~nm}$ lateral size, $3-4 \mathrm{~nm}$ height) on few layers $\mathrm{N}$-doped graphene $(\overline{\mathrm{Au}} / \mathrm{fl}-\mathrm{G})$, while the lateral sides were 0.0 .1 oriented. Comparison of the catalytic activity of $\overline{\mathrm{Au}} / \mathrm{fl}-\mathrm{G}$ films with powders of unoriented Au NPs supported on few layer graphene showed that $\overline{\mathrm{Au}} / \mathrm{fl}-\mathrm{G}$ films exhibit six orders of magnitude enhancement for three Au-catalyzed reactions, namely, the Ullmannlike homocoupling, the $\mathrm{C}-\mathrm{N}$ cross coupling and the oxidative coupling of benzene to benzoic acid as result of the defined morphology, facet orientation of $\mathrm{Au}$ nanocrystals and strong Augraphene interaction.
\end{abstract}

Catalysis by supported metal nanoparticles (MNPs) has been a very active field of research in the last thirty years. ${ }^{[1]}$ Remarkable examples of highly active and selective MNP catalysts for organic transformations including aerobic oxidations, couplings and rearrangements have been reported. ${ }^{[1]}$ Catalysis by gold constitutes one of the most salient examples of unforeseen properties for a material that appear exclusively at the nanoscale. ${ }^{[2-4]} \mathrm{A}$ constant target in this area has been the development of more efficient Au catalysts and this has been generally achieved by changing the support and by the control of the average particle size. However, according to an existing theory $[5,6]$ control of the crystallographic facet exposed by the NP should be a powerful tool to boost the catalytic activity. Experimental proof of this concept has remained elusive due to the difficulty to prepare MNPs having preferential facet orientation and there are only a few available experimental data supporting the high catalytic activity of morphologically defined Au nanocrystals. ${ }^{[6-9]}$ There has been, therefore, an interest in developing synthetic strategies for the preparation of oriented Au NPs, although the

[a] Dr. A. Primo, Mr. I. Esteve-Adell and Prof. H. García* Instituto Universitario de Tecnología Química CSIC-UPV Universidad Politécnica de Valencia

Avda. de los Naranjos s/n, 46022 Valencia, Spain E-mail: hgarcia@qim.upv.es

[b] Dr. S.N. Coman, Mrs. N. Candu and Prof. V.I. Parvulescu Department of Organic Chemistry, Biochemistry and Catalysis University of Bucharest

Bd. Regina Elisabeta nr. 4-12, 030018 Bucharest, Romania

Supporting information for this article is given via a link at the end of the document

success has been up to now limited. ${ }^{[10-13]}$ The preparation of colloidal solutions of Au nanocrystals with defined morphologies and exposed facets has recently achieved a significant step forward by using during the synthesis of Au NPs additives that coordinate strongly to one facet, arresting its growth in comparison to other crystallographic planes. ${ }^{[14,15]}$ These oriented
Au nanocrystals can be subsequently supported on a solid, aimed at adsorption of the nanocrystal with some preferential orientation, graphenes being among the currently preferred supports due to its large surface area, easy dispersabilitty and strong metal-support interaction. There are by now numerous examples showing that the catalytic activity of MNPs supported on graphene is higher than the activity of analogous MNPs supported on other carbon forms or even metal oxides. ${ }^{[16-18]}$

In the present manuscript we report the preparation of 1.1.1 facet oriented $\mathrm{Au}$ nanoplatelets of average lateral dimension 20 $\mathrm{nm}$ and 3-4 $\mathrm{nm}$ height supported on $\mathrm{N}$-doped few layers graphene films $(\overline{\mathrm{Au}} / \mathrm{fl}-\mathrm{G}, \overline{\mathrm{Au}}: 1.1 .1$ oriented $\mathrm{Au}$ nanoplatelets, $\mathrm{fl}$ : few layers, G: graphene) that exhibit about six orders of magnitude higher catalytic activity than analogous unoriented $\mathrm{Au}$ catalyst $(\mathrm{Au} / \mathrm{fl}-\mathrm{G})$ for three Au-catalyzed reactions.

The procedure disclosed herein for the preparation of $\overline{\mathrm{Au}} / \mathrm{fl}-\mathrm{G}$ is based on the simultaneous formation of $\mathrm{N}$-doped $\mathrm{G}$ by pyrolysis of nanometric films on quartz under inert atmosphere at $900{ }^{\circ} \mathrm{C}$ of a natural biopolymer (chitosan) and $\mathrm{Au}$ nanoplatelets by reduction of $\mathrm{Au}$ (III). The morphology of $\mathrm{Au}$ particles is as nanoplatelets and their dimensions range from 20 to larger than $1000 \mathrm{~nm}$ depending on the Au loading on the polymeric precursor. In a related precedent, it has reported that $\mathrm{Cu}_{2} \mathrm{O}$ nanocrystals supported on $\mathrm{G}$ exhibit a much enhanced catalytic activity. ${ }^{[19]}$

It is known that pyrolysis converts chitosan and other filmogenic natural polysaccharides into $G^{\left[{ }^{20]}\right.}$ Apparently, the fibrils of chitosan, the carbonaceous residues derived from them and the evolving N-doped $\mathrm{G}$ arrest in each step the growth of Au NPs being also formed simultaneously in the process as consequence of the reductive conditions of the $\mathrm{G}$ synthesis and the lack of solubility of $\mathrm{Au}$ on carbon. ${ }^{[21,22]}$ While many metals form metal carbides upon heating the metal with carbon at high temperatures, the noble character of $\mathrm{Au}$ results in a phase segregation leading to the synchronous formation of $\mathrm{N}$-doped $\mathrm{G}$ and Au NPs. It is remarkable that in spite of the high pyrolysis temperature the average lateral size of the Au nanoplatelets can be of only $20 \mathrm{~nm}$ for films with low Au loading $\left(\mathrm{ng} \times \mathrm{cm}^{-2}\right)$. Besides being a precursor of $\mathrm{N}$-doped $\mathrm{G}$, one of the key points in the synthesis is the ability of chitosan films to adsorb metal ions by strong interaction with the positive amino groups of the glucosamine units of the polymer fibrils and metal anions, in this case $\mathrm{AuCl}_{4}^{-}$.

The loading of $\mathrm{Au}$ NPs on the $\mathrm{G}$ film can be controlled by varying the concentration of $\mathrm{AuCl}_{4}^{-}$in the solution during impregnation of chitosan film (Scheme 1). In this way, $\mathrm{Au}$ loadings from a few $\mathrm{ng} \times \mathrm{cm}^{-2}$ up to $\mu \mathrm{g} \times \mathrm{cm}^{-2}$ on the $\overline{\mathrm{Au}} / \mathrm{fl}-\mathrm{G}$ film can be obtained in a reproducible way. The preparation procedure was repeated independently many times with 
identical $\mathrm{Au}$ nanocrystal orientation and consistent characterization data for the $\overline{\mathrm{Au}} / \mathrm{fl}-\mathrm{G}$ films. This one-step synthesis of $\overline{\mathrm{Au}} / \mathrm{fl}-\mathrm{G}$ contrast with other methods reported in the literature for the preparation of Au NPs supported on G that require prior preparation of $\mathrm{G}^{[23]}$, and even modification of $\mathrm{G}$ surface. $^{\text {[24] }}$

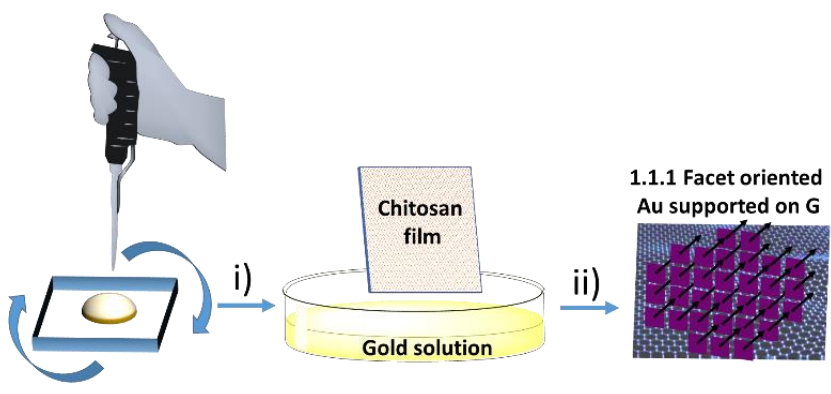

Scheme 1. Illustration of the preparation procedure for $\overline{\mathrm{Au}} / \mathrm{fl}-\mathrm{G}$ films .(i) Spin coating of an aqueous chitosan solution on quartz $\left(2 \times 2 \mathrm{~cm}^{2}\right)$; (ii) Adsorption of $\mathrm{AuCl}_{4}{ }^{-}$on chitosan film before pyrolysis under inert atmosphere at $900{ }^{\circ} \mathrm{C}$.

Besides $\overline{\mathrm{Au}} / \mathrm{fl}-\mathrm{G}$ films, for the sake of comparison, Au/fl-G powders obtained by supporting preformed Au NPs on N-doped $G$ were also synthesized (see Experimental section).

XRD of $\overline{\mathrm{Au}} / \mathrm{fl}-\mathrm{G}$ samples (loading of $\mathrm{Au} 3.2 \mathrm{ng} \times \mathrm{Cm}^{-2}$ ) did not exhibit any peak, due to the low film thickness and Au loading. In contrast, thicker samples of multilayer $\mathrm{G}$ (ml-G, ml: multilayer) (thickness $>40 \mathrm{~nm}$ ) containing Au exhibit in XRD a single peak at $39^{\circ}$ accompanied by a weaker 2.2 .2 peak at $82^{\circ}$, characteristic of 1.1 .1 oriented crystals. For the sake of comparison, Figure 1 shows XRD of $\overline{\mathrm{Au}} / \mathrm{ml}-\mathrm{G}$ (Au loading $2.4 \mu \mathrm{g} \times \mathrm{cm}^{-2}$ ) compared to the one obtained for $\mathrm{Au} / \mathrm{fl}-\mathrm{G}$ (Au loading 1 wt\%) lacking any preferential orientation. In the last case, XRD presents more diffraction peaks that correspond indisputably to ffc Au crystals (JCPDS No 01-1174). As it can be seen in Figure 1 the consequence of the simultaneous formation of $\mathrm{N}$-doped $\mathrm{G}$ and $\mathrm{Au}$ NPs is the orientation of the Au NPs crystals.

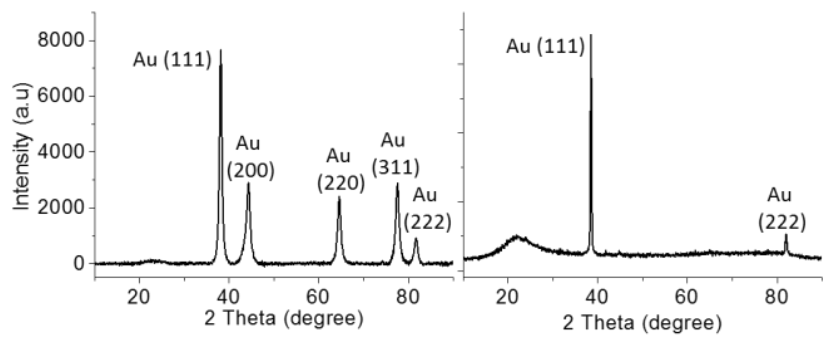

Figure 1. XRD patterns of $\mathrm{Au} / \mathrm{fl}-\mathrm{G}\left(1 \mathrm{wt} \%\right.$ ) (left) and $\overline{\mathrm{Au}} / \mathrm{ml}-\mathrm{G}\left(2.4 \mu \mathrm{g} \times \mathrm{cm}^{-2}\right)$ (right) showing the different indexation of the peaks. The broad band at about $22^{\circ}$ observed in the $\overline{\mathrm{Au}} / \mathrm{ml}-\mathrm{G}$ that is almost absent in the Au/fl-G corresponds to the characteristic diffraction of $\mathrm{ml}-\mathrm{G}$.

One possible explanation to rationalize the preferential growth of the 1.1.1 facets is the combination of higher thermodynamic stability of this facet, together with a templation effect of $\mathrm{N}$ doped $\mathrm{G}$ on the growth of Au nanoplatelets. This explanation is based on the accepted mechanism for the chemical vapor deposition of $\mathrm{G}$ on metal surfaces. ${ }^{[21,25,26]}$ In these syntheses of
$\mathrm{G}$, it is accepted that carbon atoms start to deposit on the metal surface and the metal atoms template the hexagonal arrangement of the growing $G$ formed epitaxially on the meta surface. In the present case, the situation would be the reverse and as $G$ sheets are formed in the pyrolysis from chitosan, $A u$ atoms evolving from the polymeric fibrils will appear on the surface of $G$, resulting in an epitaxial growth of the 1.1.1 facets of $\mathrm{Au}$ nanoplatelets deposited on $\mathrm{G}$, maximizing the interaction between $\mathrm{Au}$ atoms and $\mathrm{G}$ (see Supplementary information Fig. S1 for an illustration of the process).

Additional direct information of the morphology of Au crystals and their preferential 1.1.1 facet orientation, regardless the loading of $\mathrm{Au}$ and the thickness of $\mathrm{G}$ was obtained by electron microscopy. TEM images of $\overline{\mathrm{Au}} / \mathrm{G}$ (both $\mathrm{fl}$ or $\mathrm{ml}$ ) samples reveal that the preferential morphology of $A u$ nanocrystals is nanoplatelets whose size distribution and average dimensions depend on the concentration of $\mathrm{Au}$ on chitosan. Low-loading $\overline{\mathrm{Au}} / \mathrm{fl}-\mathrm{G}$ films have a Au content of $3.2 \mathrm{ng} \times \mathrm{cm}^{-2}\left(16.2 \mathrm{pmol} \times \mathrm{cm}^{-2}\right)$. For low-loading $\overline{\mathrm{Au}} / \mathrm{fl}-\mathrm{G}$ films that do not exhibit any XRD pattern, the average lateral dimension of the nanoplatelets determined by TEM images was about $20 \mathrm{~nm}$ (see Figure 2 and supporting information Figures S2 and S3). A few nanoplatelets were accidentally detached from the $G$ surface, allowing estimation of a 3-4 $\mathrm{nm}$ for the thickness of these nanoplatelets (see marked nanoplatelets in Figure S4 of the supplementary information), an estimation that was confirmed more accurately by AFM. It is worth noting that these relatively small average dimensions are remarkable considering the high temperature required in the synthesis of $\overline{\mathrm{Au}} / \mathrm{fl}-\mathrm{G}$ films and the known tendency of Au NPs to undergo aggregation at high temperatures. For these films with low Au loading, as well as also for those with larger Au loading, transmission Kikuchi diffraction ${ }^{[27]}$ of relatively large film areas $\left(2.5 \times 2.5 \mu^{2}\right)$ shows indisputably the preferential 1.1.1 facet orientation of Au nanoplatelets (see Figure 2 and supplementary information Figure S5) as it was already commented for the XRD of the thicker $\overline{\mathrm{Au}} / \mathrm{ml}-\mathrm{G}$ films. Comparison of the FESEM image showing the presence of Au with that of the 1.1.1 facet based on the transmission electron diffraction pattern shows a coincidence over $90 \%$. Moreover, these images also reveal the strict 0.0 .1 orientation of the planes perpendicular to the larger 1.1.1 surface. Another interesting observation related to the interplay between $A u$ and $G$ is the presence on $G$ of some pathways around $A u$ nanoplatelets with significantly decreased thickness of the $G$ sheet. It seems that formation of $A u$ nanoplatelets causes depletion on the number of $G$ layers, possibly due to the activity of $\mathrm{Au}$ nanoplatelets as catalytic sites improving graphitization by removal of residual oxygenated functional groups and, also the random walk of Au nanocrystals on the $G$ sheets defining some pathways. AFM measurements of $\overline{\mathrm{Au}} / \mathrm{fl}-\mathrm{G}$ also confirm the nanoplatelet morphology of $\mathrm{Au}$ crystals and their uniform height about 3-4 nm. Figure 3 and Supplementary information Figure $\mathrm{S} 6$ present some top views of $\overline{\mathrm{Au}} / \mathrm{fl}-\mathrm{G}$ as well as measurements of the height of $A u$ nanoplatelets distributed on a relatively large area of the $\overline{\mathrm{Au}} / \mathrm{fl}-\mathrm{G}$ film. Cuts on the film indicate that the thickness of the $G$ is about $20 \mathrm{~nm}$, although there are certain areas around $A u$ crystals with $G$ thickness about $8 \mathrm{~nm}$. The existence of certain pathways around $\mathrm{Au}$ nanoplatelets noticed in FESEM is also observed in the top AFM 
images of $\overline{\mathrm{Au}} / \mathrm{fl}-\mathrm{G}$ that show that most $\mathrm{Au}$ nanoplatelets are located on valleys of the $G$ film.
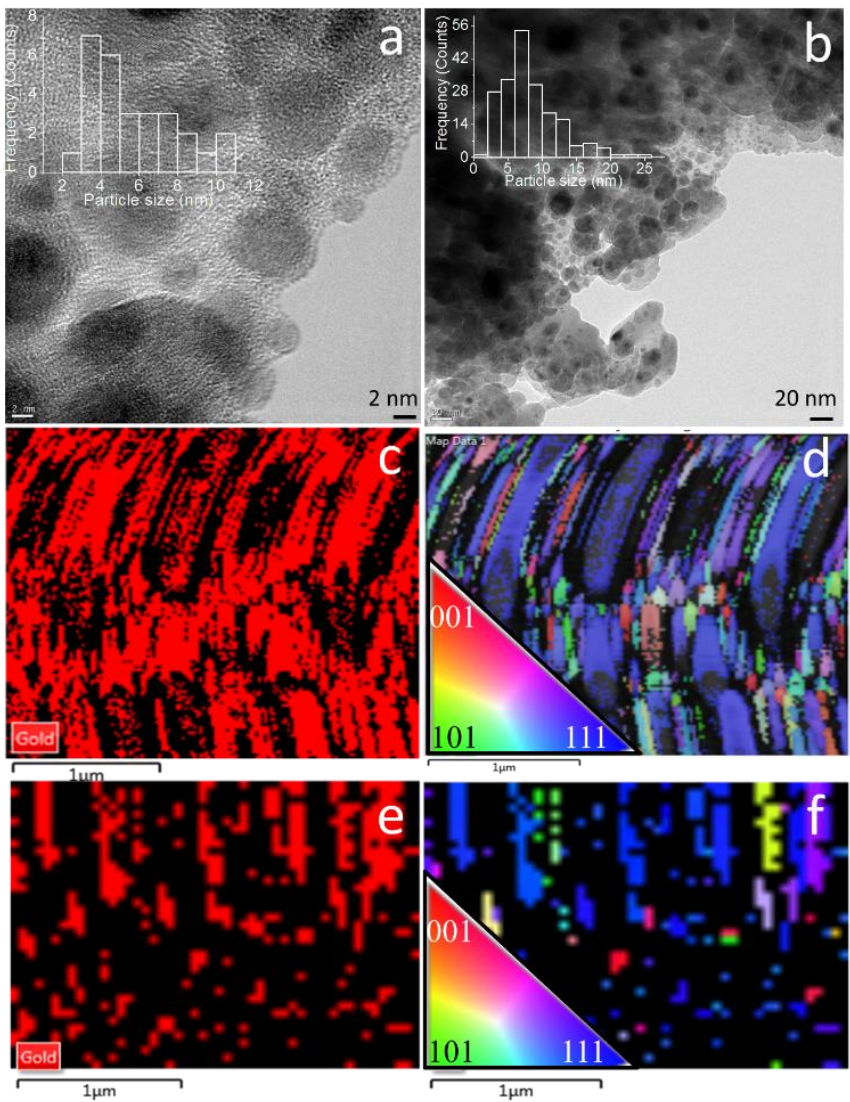

Figure 2. a) and b) TEM images of $\overline{\mathrm{Au}} / \mathrm{fl}-\mathrm{G}\left(3.2 \mathrm{ng} \times \mathrm{cm}^{-2}\right)$ at two different magnifications, showing as insets the corresponding particle size distribution c) and e) EDS analysis of Au of two different films (Au loading $\left(3.2 \mathrm{ng} \times \mathrm{cm}^{-2}\right.$ ) showing the presence of $\mathrm{Au}$ in red; d) and f) facet orientation of the nanoplatelets presenting in blue the 1.1.1 facet and in pink the 0.0.1 planes obtained by transmission Kikuchi diffraction. ${ }^{[2]}$ The color codes are indicated as inset of frames $d$ and $f$.
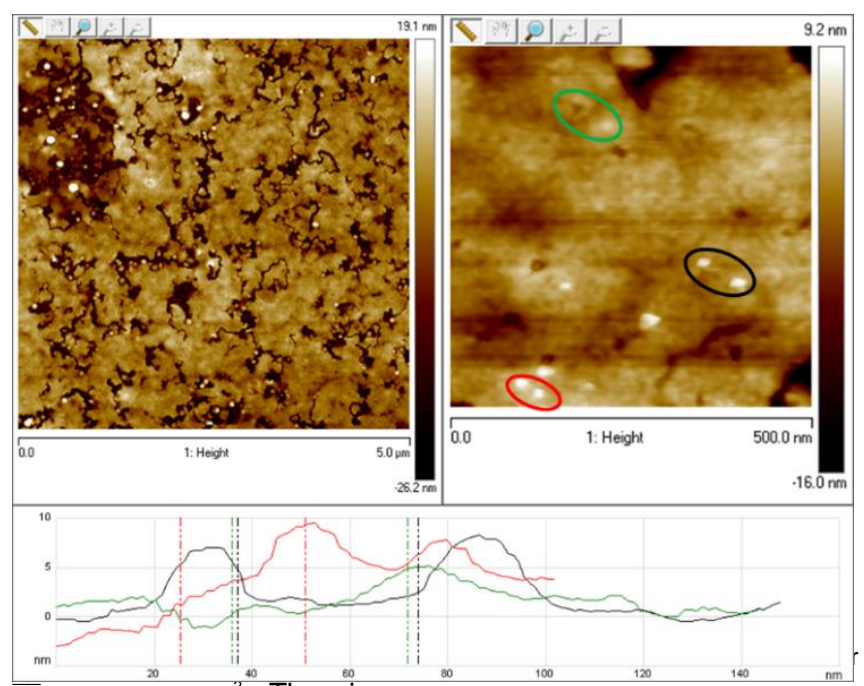

$\overline{\mathrm{Au}} / \mathrm{fl}-\mathrm{G}\left(3.2^{20} \mathrm{ng} \times \mathrm{Cm}^{-2}\right)$. The size (height and lateral dimension) of five $\mathrm{Au}$ nanoplatelets circled in the right frame are presented in the bottom part of the image. Notice that according to the low magnification image shown in the left frame, Au nanoplatelets are consistently located on valleys of the G film of height lower than $10 \mathrm{~nm}$.
Raman spectrum of $\overline{\mathrm{Au}} / \mathrm{fl}-\mathrm{G}$ is shown in Figure 4. As it can be seen there, the Raman spectrum shows the characteristic $\mathrm{G}$ and $\mathrm{D}$ bands appearing at 1600 and $1350 \mathrm{~cm}^{-1}$ accompanied by a broad 2D band around $2700 \mathrm{~cm}^{-1}$, expected for $\mathrm{G}$ obtained by pyrolysis of chitosan. The $I_{G} / I_{D}$ ratio was 1.13 that is a common value for this $\mathrm{G}$ having $\mathrm{N}$ doping (from glucosamine units of chitosan) and residual $\mathrm{O}$ functionalities. ${ }^{[28]}$ An abnormal feature of the Raman spectrum was, however, the appearance of sharp peak at about $2850 \mathrm{~cm}^{-1}$ on top of the broad 2D band. Appearance of a narrow sharp $2 \mathrm{D}$ peak is generally associated to the presence of single or double $\mathrm{G}$ layers. It is likely that this sharp 2D not observed in analogous $G$ samples arises as consequence of the influence of Au nanoplatelets on $G$, making the $G$ film in the surroundings of the $A u$ nanoplatelets thinner and increasing the intensity of the band by plasmon Raman enhancement. It is noteworthy that the position of the 2D band appears generally at values below $2750 \mathrm{~cm}^{-1} .{ }^{[24]}$ Precedents in the literature have also observed this shift and attributed it to charge transfer from $G$ to the adsorbate. ${ }^{[29]}$ Accordingly, the abnormal shift of the $2 \mathrm{D}$ band toward higher values could be attributed to a charge transfer from $\mathrm{G}$ to Au nanoplatelets due to the different work function of the two components.
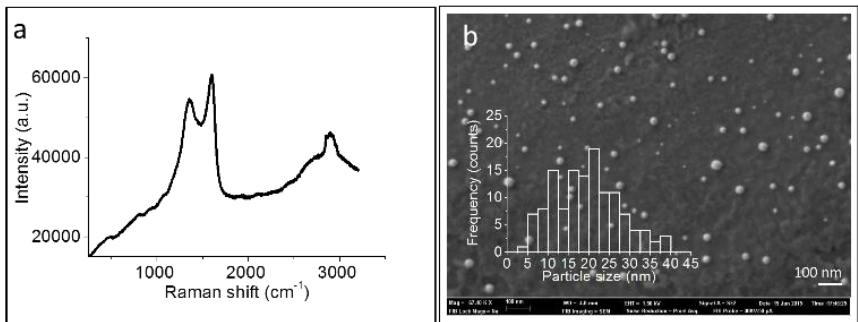

Figure 4. (a) Raman spectrum of $\overline{\mathrm{Au}} / \mathrm{fl}-\mathrm{G}\left(3.2 \mathrm{ng} \times \mathrm{cm}^{-2}\right)$ where the presence of a sharp $2 \mathrm{D}$ band on top of a broad $2 \mathrm{D}$ background can be clearly observed at $2850 \mathrm{~cm}^{-1}$. (b) SEM image of $\overline{\mathrm{Au}} / \mathrm{fl}-\mathrm{G}\left(3.2 \mathrm{ng} \times \mathrm{cm}^{-2}\right)$. The inset shows the particle size distribution.

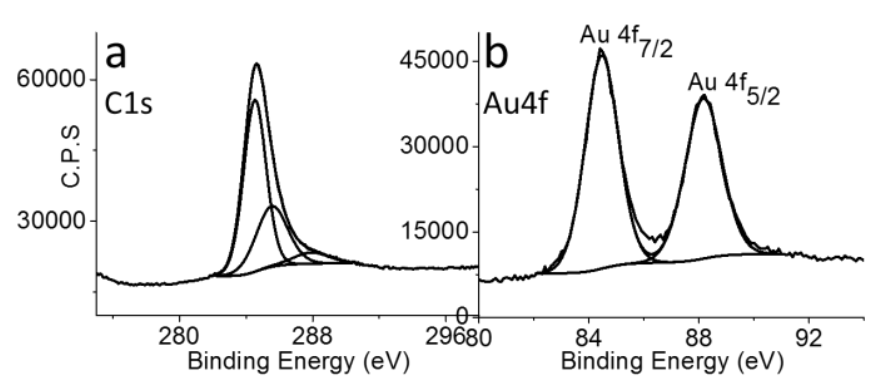

Figure 5. XPS $C$ 1s (a) and $A u 4 f(b)$ peaks as well as their best fitting to individual components recorded for the $\overline{\mathrm{Au}} / \mathrm{fl}-\mathrm{G}$ sample $\left(3.2 \mathrm{ng} \times \mathrm{cm}^{-2}\right)$.

X-ray photoelectron spectroscopy (XPS) establishes the composition and distribution of each element in the material into different coordination environments. As expected $\overline{\mathrm{Au}} / \mathrm{fl}-\mathrm{G}$ films contain C (89 at\%), N (1 at\%), O (5 at\%) and Au (4 at\%). Figure 5 and Supplementary information Figure S7 show also the highresolution $\mathrm{C}$ 1s and the $\mathrm{Au} 4 \mathrm{f}$ peaks recorded for $\overline{\mathrm{Au}} / \mathrm{fl}-\mathrm{G}$. The experimental $C$ 1s peak can be deconvoluted into three main contributions of 66,28 and $6 \%$ corresponding to graphenic sp2 
(284.5 eV), $\mathrm{C}=\mathrm{O} / \mathrm{C}-\mathrm{N}(285.5 \mathrm{eV})$ and $\mathrm{CO}_{2} \mathrm{H}(288.5 \mathrm{eV}) \mathrm{C}$ atoms, respectively. The $\mathrm{Au} 4 \mathrm{f}$ core level peak presents the expected two contributions due to $A u 4 f 5 / 2$ and $A u$ 4f7/2 separated by $3.73 \mathrm{eV}$ arising from spin-orbit splitting at 88.18 and $84.45 \mathrm{eV}$, respectively. The shape of the experimental Au $4 \mathrm{f}$ peak indicates that there is a single component, $\mathrm{Au}(0)$, without significant contribution of $A u(I)$ and $A u$ (III). The binding energy values of the $\mathrm{Au} 4 \mathrm{f}$ peak in $\overline{\mathrm{Au}} / \mathrm{fl}-\mathrm{G}$ are, however, shifted by $0.4 \mathrm{eV}$ to higher values respect to those of bulk $\mathrm{Au}$. This binding energy shift is again compatible with the occurrence of a strong Ausupport interaction.

Supported Au NPs exhibit a remarkable catalytic activity for a series of reactions including selective oxidations, reductions and couplings. ${ }^{[2,30,31]}$ To evaluate the influence of preferential 1.1.1 facet orientation and the strong metal-support interaction on the catalytic performance, the activity of $\overline{\mathrm{Au}} / \mathrm{fl}-\mathrm{G}$ film (quartz plates, $3.2 \mathrm{ng} \times \mathrm{cm}^{-2}$ ) was compared with that of an analogous Au/fl-G sample in which Au NPs obtained by the polyol method have been deposited on fl-G at $0.1 \mathrm{wt} \%$ Au content. In the literature it is well known that polyol reduction renders Au NPs of about 5 $\mathrm{nm}$ average size $.^{[32,33]} \mathrm{fl}-\mathrm{G}$ was obtained by pyrolysis of chitosan and subsequent exfoliation of the turbostratic carbon residue by sonication. ${ }^{[28]}$ Preformed Au NPs were subsequently adsorbed on $\mathrm{fl}-\mathrm{G}$. Au/fl-G exhibited the XRD shown in Figure 1 lacking any preferential facet orientation. The comparison of the influence of facet orientation and strong metal-support interaction was evaluated for two representative coupling reactions, namely, the Ullmann-like homocoupling of iodobenzene to biphenyl (Eq. 1) and the C-N cross coupling of anilines (Eq. 2) and for one oxidation reaction such as the degradative oxidation of benzene to benzoic acid (Eq. 3).

Control experiments showed that fl-G does not exhibit any noticeably catalytic activity in comparison to that of the samples containing $\mathrm{Au}$. In contrast, $\overline{\mathrm{Au}} / \mathrm{fl}-\mathrm{G}$ films exhibited a remarkable catalytic activity. Hot filtration tests removing the $\overline{\mathrm{Au}} / \mathrm{fl}-\mathrm{G}$ plates after $8 \mathrm{~h}$ reaction time showed that the conversion stops in all cases. In addition analysis of Au present in the liquid phase after removal of $\overline{\mathrm{Au}} / \mathrm{fl}-\mathrm{G}$ at final reaction time did not allow the detection of $\mathrm{Au}$. When the catalytic activity of unoriented Au/fl-G sample was tested at the same $\mathrm{Au} /$ substrate mol ratio as $\overline{\mathrm{Au}} / \mathrm{fl}-\mathrm{G}$ films (about $10^{-9}$ ), no catalytic activity was observed. However, at higher Au/substrate mol ratio (about $10^{-3}$ ), Au/fl-G was also significantly active. No leaching was observed also for $\mathrm{Au} / \mathrm{fl}-\mathrm{G}$ powders. The results are collected in Table 1.

As it can be seen there, Ullmann-like homocoupling of iodobenzene affords biphenyl as major product, accompanied by minor amounts of ortho and para isomers of iodobiphenyl. Similarly, the reaction of aniline and bromobenzene under basic conditions affords diphenylamine accompanied ( $\overline{\mathrm{Au}} / \mathrm{fl}-\mathrm{G})$ or not $(\mathrm{Au} / \mathrm{fl}-\mathrm{G})$ by triphenylamine, arising from the double $\mathrm{C}-\mathrm{N}$ coupling. In the case of the oxidative degradation of benzene by phenyiodoso diacetate, biphenyl was the primary product that undergoes efficient degradation to form benzoic acid. As it can be seen in Eq. 4, the carbon of the carboxylic acid group of benzoic acid derives from the oxidation of biphenyl intermediate. The most remarkable fact from Table 1 is that the turnover number values obtained for $\overline{\mathrm{Au}} / \mathrm{fl}-\mathrm{G}$ film are for every reaction over six orders of magnitude higher than those of $\mathrm{Au} / \mathrm{fl}-\mathrm{G}$. This higher catalytic activity is due to the high activity of minute amounts of Au when deposited as oriented nanoplatelets on fl-G, the preferential orientation of the $A u$ nanoplatelets and the occurrence of strong Au-G interaction evidenced by the particle size, the 2D band shift in Raman and the Au $4 f$ binding energy in XPS. When $\overline{\mathrm{Au}} / \mathrm{fl}-\mathrm{G}$ film with higher Au loading $\left(2.4 \mu \mathrm{g} \times \mathrm{cm}^{-2}\right)$ was used as catalyst, similar catalytic activities at final reaction times were observed, but turnover numbers of these unoptimized loading were about two orders of magnitude lower, probably due to the larger Au nanocrystal size (up to $1000 \mathrm{~nm}$ ). At the end of the reaction, $\overline{\mathrm{Au}} / \mathrm{fl}-\mathrm{G}$ film becomes detached from the quartz plate, but could be recovered from the reaction mixture. A second use of the detached $\overline{\mathrm{Au}} / \mathrm{fl}-\mathrm{G}$ catalyst for the oxidative degradation showed similar catalytic activity $(22 \%)$ as that of the fresh catalyst. Furthermore, SEM images of the used $\overline{\mathrm{Au}} / \mathrm{fl}-\mathrm{G}$ catalyst did not show significant change in the morphology and sized of the $\mathrm{Au}$ nanoplatelets (see supplementary information Figure S8).

Thus, in the present manuscript we have shown a reliable procedure for the preparation of 1.1 .1 facet oriented $\mathrm{Au}$ nanoplatelets supported on $\mathrm{fl}-\mathrm{G}$ by pyrolysis at $900{ }^{\circ} \mathrm{C}$ of a chitosan precursor containing $\mathrm{AuCl}_{4}^{-}$. The resulting $\overline{\mathrm{Au}} / \mathrm{fl}-\mathrm{G}$ films exhibit an extremely high catalytic activity for coupling and oxidation reactions compared to unoriented $\mathrm{Au} / \mathrm{fl}-\mathrm{G}$ analogues. Although further work is necessary to fully clarify the origin of the remarkable catalytic activity, it seems that it derives from the combination of strong metal-support interaction and preferential facet orientation. Another issue is to show the general applicability of this procedure for other metals that do not dissolve on carbon and assessment of any preferential facet orientation.

Table 1. Comparative activity data determined for $\overline{\mathbf{A u}} / \mathrm{fl}-\mathrm{G}$ film and $\mathrm{Au} / \mathrm{fl}-\mathrm{G}$

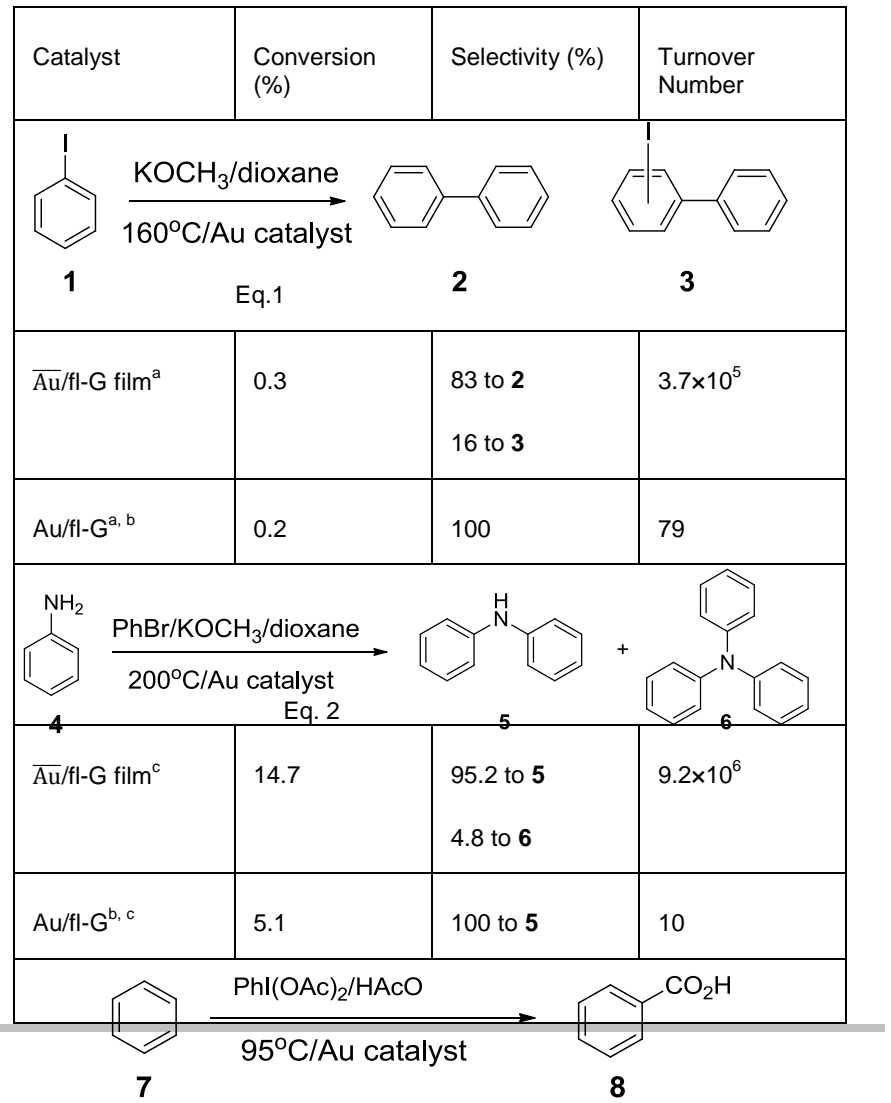




\begin{tabular}{|l|l|l|l|}
\hline \multicolumn{5}{|c|}{ Eq. 3 } & $1.4 \times 10^{7}$ \\
\hline$\overline{\mathrm{Au} / \mathrm{fl}-G}$ film & \multicolumn{1}{|c|}{23.9} & 100 & 21.8 \\
\hline Au/fl-G & 35.2 & 100 & $\mathrm{~b}, \mathrm{~d}$ \\
\hline
\end{tabular}

[a] Reaction conditions: lodobenzene $2.00 \mathrm{mmol}, 4 \mathrm{~mL}$ 1,4-dioxane, base $=2$ mmol $\left(\mathrm{KOCH}_{3}\right)$, reaction temperature: $160^{\circ} \mathrm{C}$, time $24 \mathrm{~h}$, catalyst: $\overline{\mathrm{Au}} / \mathrm{fl}-\mathrm{G}$ films $1 \times 1 \mathrm{~cm}^{2}$ or Aufl-G powder $10 \mathrm{mg}$. [b] when exactly the same total amount of $\mathrm{Au}$ present in $\overline{\mathrm{Au}} / \mathrm{fl}-\mathrm{G}$ is used for $\mathrm{Au} / \mathrm{fl}-\mathrm{G}$, no reaction was observed (see text for comments); [c] Reaction conditions: Bromobenzene 1,2 mmol, aniline 1 $\mathrm{mmol}, \mathrm{KOCH}_{3} 2.1 \mathrm{mmol}, 1,4$-dioxane $4 \mathrm{~mL}$, reaction temperature: $200^{\circ} \mathrm{C}$, time $24 \mathrm{~h}$. [d] Reaction conditions: Benzene $10 \mathrm{mmol}, \mathrm{Phl}(\mathrm{OAc})_{2} 1 \mathrm{mmol}$, solven $17 \mathrm{mmol} \mathrm{HOAc}$, reaction temperature: $95{ }^{\circ} \mathrm{C}$, time $=24 \mathrm{~h}$, catalyst: $\overline{\mathrm{Au}} / \mathrm{fl}-\mathrm{G}$ films $1 \times 1 \mathrm{~cm}^{2}$ or $\overline{\mathrm{Au}} / \mathrm{fl}-\mathrm{G}$ powder $10 \mathrm{mg}$.

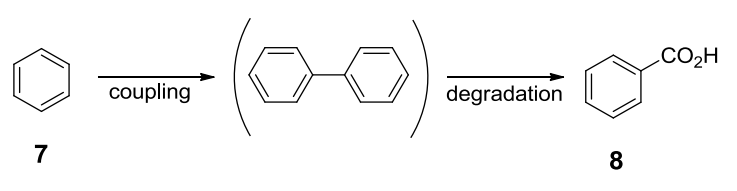

\section{Experimental Section}

Catalysts preparation.

Synthesis of few-layers graphene (fl-G). Alginic acid sodium salt from brown algae (Sigma) was pyrolyzed under argon atmosphere using the following oven program: annealing at $200{ }^{\circ} \mathrm{C}$ for $2 \mathrm{~h}$ and, then, heating at $10{ }^{\circ} \mathrm{C} / \mathrm{min}$ up to $900{ }^{\circ} \mathrm{C}$ for $6 \mathrm{~h}$. The resulting graphitic powder was sonicated at $700 \mathrm{~W}$ for $1 \mathrm{~h}$ in water and the residue removed by centrifugation to obtain $\mathrm{fl}-\mathrm{G}$ dispersed in water.

Au NPs deposition on $\mathrm{fl}-\mathrm{G}(0.1 \% w \mathrm{w})$. $\mathrm{fl}-\mathrm{G}$ from alginate pyrolysis $(100 \mathrm{mg})$ was added to ethylene glycol $(40 \mathrm{~mL})$ and the mixture was sonicated at $700 \mathrm{~W}$ for $1 \mathrm{~h}$ to obtain dispersed fl-G. $\mathrm{HAuCl}_{4}(0.2 \mathrm{mg})$ was added to the reaction mixture and $\mathrm{Au}$ metal reduction was then performed at $120{ }^{\circ} \mathrm{C}$ for $24 \mathrm{~h}$ under continuous stirring. The Au/fl-G were finally separated by filtration and washed exhaustively with water and with acetone. The resulting material was dried in a vacuum desiccator at $110^{\circ} \mathrm{C}$ to remove the remaining water. The amount of gold present on the films was determined by ICP-OES by immersing the plates into aqua regia at room temperature for $3 \mathrm{~h}$ and analysing the Au content of the resulting solution.

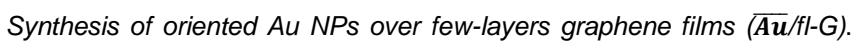
$0.5 \mathrm{~g}$ of chitosan from Aldrich (low molecular weight) was dissolved in water with a small quantity of acetic acid $(0.23 \mathrm{~g})$, necessary for complete dissolution of chitosan. The solution was filtered through syringe of 0.45 $\mu \mathrm{m}$ diameter pore to remove impurities present in commercial chitosan. The films were supported on a quartz plate $\left(2 \times 2 \mathrm{~cm}^{2}\right)$ by casting $500 \mu \mathrm{L}$ of filtered solution at $4000 \mathrm{rpm}$ during $1 \mathrm{~min}$. In the second synthesis step the obtained chitosan films were immersed in a $\mathrm{HAuCl}_{4}$ solution $(1 \mathrm{mM}$ or $0.01 \mathrm{mM}$ ) during $1 \mathrm{~min}$. The pyrolysis was performed under argon atmosphere using the following oven program: heating rate at $5^{\circ} \mathrm{C} / \mathrm{min}$ up to $900{ }^{\circ} \mathrm{C}$ for $2 \mathrm{~h}$. The amount of gold present on the films was determined by ICP-OES by immersing the plates into aqua regia at room temperature for $3 \mathrm{~h}$ and analysing the Au content of the resulting solution.

General procedure for the Ullmann-like homocoupling. All reagents were purchased from Sigma-Aldrich and used as received without any purification. To a solution of iodobenzene $(2.00 \mathrm{mmol})$ in $4 \mathrm{ml}$ of 1,4 dioxane, $\mathrm{KOCH}_{3}(2 \mathrm{mmol})$ and catalyst $\left(1 \times 1 \mathrm{~cm}^{2}\right.$ plate of $\overline{\mathrm{Au}} / \mathrm{fl}-\mathrm{G}$ film or $10 \mathrm{mg}$ of $\mathrm{Au} / \mathrm{fl}-\mathrm{G}$ powder, $0.1 \mathrm{Au}$ loading) were added. The resulting mixture was stirred in an autoclave for $24 \mathrm{~h}$ at $160^{\circ} \mathrm{C}$. After reaction, the catalyst was collected by filtration and the reaction products were analyzed and identified by GC-MS (THERMO Electron Corporation instrument, Trace GC Ultra and DSQ, TraceGOLD): TG-5SilMS column with the following specifications: $30 \mathrm{~m} \times 0.25 \mathrm{~mm} \times 0.25 \mu \mathrm{m}$, working with a temperature program that starts at $50{ }^{\circ} \mathrm{C}$ maintained for 2 min and afterwards increasing the temperature at a rate of $10^{\circ} \mathrm{C} / \mathrm{min}$ up to $250{ }^{\circ} \mathrm{C}$ that was maintained for $10 \mathrm{~min}$, resulting in a total run time of $32 \mathrm{~min}$ The pressure of He used as the carrier gas was 0.38 Torr. Mass spectra of the products were acquired at 70,000 resolutions. Biphenyl (2): MS (EI) m/z (rel.int): 154 (M+, 100\%), 128 (4), 115 (4), 76 (12), 63 (3), 51 (3); o-lododiphenyl (3a): MS (EI) m/z 23(rel.int): 280 ( M+, 66.8\%), 152 (100) 140 (8), 127 (8), 76 (14), 63 (4); p-iododiphenyl (3b): MS (El) m/z (rel.int): 280 ( M+, 100\%), 152(78), 140 (6), 127 (7), 76 (12), 63 (3).

General procedure for the $\mathbf{C}-\mathbf{N}$ reaction. To a solution of bromobenzene $(1.2 \mathrm{mmol})$ and aniline $(1 \mathrm{mmol})$ in $4 \mathrm{ml}$ of 1,4-dioxane, $\mathrm{KOCH}_{3}(2,1 \mathrm{mmol})$ and catalyst were added. The resulting mixture was stirred in an autoclave for $24 \mathrm{~h}$ at $200{ }^{\circ} \mathrm{C}$. After the reaction, the catalyst was collected by filtration and the reaction products were analyzed and identified by GC-MS (THERMO Electron Corporation instrument).

Diphenylamine (5): MS (EI) m/z (rel.int): 169 (M+, 100\%), 141 (5), 115 (4), 84 (12), 77 (5), 51 (3); Triphenylamine (6): MS (EI) m/z (rel.int): 245 ( M+, 100\%), 167 (22), 141 (12), 115 (9), 77 (10), 51 (5).

General procedure for the oxidative coupling reaction. To a solution of benzene $(10 \mathrm{mmol})$ and $1 \mathrm{mmol}$ of oxidant [Phl(OAc) $)_{2}$, acetic acid (17 mmol) and catalyst were added. The mixture was stirred for $24 \mathrm{~h}$ at $95{ }^{\circ} \mathrm{C}$ in autoclave, and then quenched with water $(10 \mathrm{~mL})$. The reaction mixture was extracted with EtOAc $(3 \times 10 \mathrm{~mL})$ and the combined organic layer was washed with saturated $\mathrm{NaHCO}_{3}(2 \times 20 \mathrm{~mL})$, brine $(10 \mathrm{ml})$, dried over $\mathrm{Na}_{2} \mathrm{SO}_{4}$, filtered and concentrated. The products were analyzed and identified by using GC-MS (THERMO Electron Corporation instrument) and a Bruker Advance III UltraShield $500 \mathrm{MHz}$ spectrometer operating at $500,13 \mathrm{MHz}$ for ${ }^{1} \mathrm{H}$ NMR, $125,77 \mathrm{MHz}$ for ${ }^{13} \mathrm{C} \mathrm{NMR}$. Turnover numbers were calculated by dividing the moles of product formed by the moles of Au present in the catalyst at final reaction time.

\section{Acknowledgements}

Financial support by the Spanish Ministry of Economy and Competitiveness (Severo Ochoa and CTQ2012-32315) and by the Generalidad Valenciana (Promoteo 2013-019) is gratefully acknowledged. I.E-A. thanks the Spanish Ministry for a postgraduate scholarship. We are thankful to Mrs. Amparo Forneli for her assistance in sample preparation.

Keywords: Heterogeneous catalysis • oriented gold nanoparticles $\cdot$ graphene as support $\bullet$ coupling catalysts

[1] D. Astruc, F. Lu, J. R. Aranzaes, Angew. Chem., Int. Ed. 2005, 44 7852-72.

[2] A. S. K. Hashmi, G. J. Hutchings, Angew. Chem. Int. Ed. 2006, 45, 7896-936.

[3] A. S. K. Hashmi, Angew. Chem., Int. Ed. 2005, 44, 6990-3

[4] M. Haruta, S. Tsubota, T. Kobayashi, H. Kageyama, M. J. Genet, B Delmon, J. Catal. 1993, 144, 175-92.

[5] M. Boronat, D. Combita, P. Concepción, A. Corma, H. García, R Juárez, S. Laursen, J. de Dios López-Castro, J. Phys. Chem. C 2012, $116,24855-67$.

[6] J. Lin, H. Abroshan, C. Liu, M. Zhu, G. Li, M. Haruta, J. Catal. 2015 330, 354-61.

[7] V. K. Kanuru, G. Kyriakou, S. K. Beaumont, A. C. Papageorgiou, D. J. Watson, R. M. Lambert, J. Am. Chem. Soc. 2010, 132, 8081-6.

[8] Q. Zhang, H. Wang, ACS Catal. 2014, 4, 4027-33. 
[9] G. Li, C. Zeng, R. Jin, J. Phys. Chem. C 2015, 119, $11143-7$.

[10]B. Goris, S. Bals, W. Van den Broek, E. Carbó-Argibay, S. GómezGranza, L. M. Liz-Marzán, G. Van Tendeloo, Nat Mater 2012, 11, 930-5.

[11]A. R. Tao, S. Habas, P. Yang, Small 2008, 4, 310-25

[12]P. Prodhomme, S. Warren, R. Cortes, H. F. Jurca, F. Maroun, P. Allongue, Chemphyschem 2010, 11, 2992-3001.

[13] Y. G. Sun, Y. N. Xia, Science 2002, 298, 2176-9.

[14] C.-C. Chen, C.-H. Hsu, P.-L. Kuo, Langmuir 2007, 23, 6801-6.

[15]C. J. Johnson, E. Dujardin, S. A. Davis, C. J. Murphy, S. Mann, J. Mater. Chem. 2002, 12, 1765-70.

[16]X. Chen, G. Wu, J. Chen, X. Chen, Z. Xie, X. Wang, J. Am. Chem. Soc.2011, 133, 3693-5.

[17] S. Guo, S. Sun, J. Am. Chem. Soc. 2012, 134, 2492-5.

[18] J. Albero, H. Garcia, J. Mol. Catal. A 2015, 408, 296-309.

[19]A. Primo, I. Esteve-Adell, J. F. Blandez, D. A., M. Alvaro, N. Candu, S N. Coman, V. I. Parvulescu, H. Garcia, Nat. Commun. 2015, doi 2015/ncomms11406a.

[20] A. Primo, P. Atienzar, E. Sanchez, J. M. Delgado, H. Garcia, Chem. Commun. 2012, 48, 9254-6.

[21]X. Li, W. Cai, J. An, S. Kim, J. Nah, D. Yang, R. Piner, A Velamakanni, I. Jung, E. Tutuc, S. K. Banerjee, L. Colombo, R. S. Ruoff, Science 2009, 324, 1312-4.
[22]D. Takagi, Y. Kobayashi, H. Hlbirio, S. Suzuki, Y. Homma, Nano Let. 2008, 8, 832-5.

[23]G. Goncalves, P. A. A. P. Marques, C. M. Granadeiro, H. I. S

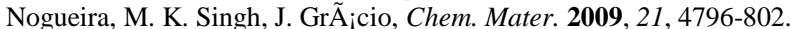

[24]M. Quintana, K. Spyrou, M. Grzelczak, W. R. Browne, P. Rudolf, M. Prato, ACS Nano 2010, 4, 3527-33.

[25] W. Liu, H. Li, C. Xu, Y. Khatami, K. Banerjee, Carbon 2011, 49, 4122-30.

[26]C. Mattevi, H. Kima, M. Chhowalla, J. Mater. Chem. 2010, 21, $3324-$ 34.

[27]P. W. Trimby, Ultramicroscopy 2012, 120, 16-24

[28]A. Primo, E. Sánchez, J. M. Delgado, H. García, Carbon 2014, 68, 777-83.

[29] A. C. Ferrari, D. M. Basko, Nat Nano 2013, 8, 235-46.

[30]M. Stratakis, H. Garcia, Chem. Rev. 2012, 112, 4469-506.

[31]A. S. K. Hashmi, Chem. Rev. 2007, 107, 3180-211.

[32]C. Luo, Y. Zhang, X. Zeng, Y. Zeng, Y. Wang, J. Coll. Inter. Sci. 2005, 288, 444-8.

[33]B. K. Park, S. Jeong, D. Kim, J. Moon, S. Lim, J. S. Kim, J. Coll. Inter. Sci. 2007, 311, 417-24. 
Entry for the Table of Contents

\section{COMMUNICATION}

Graphene and 1.1.1 facet oriented Au nanoparticles form simultaneously upon pyrolysis of chitosan embedding $\mathrm{AuCl}_{4}{ }^{-}$, exhibiting a high catalytic activity

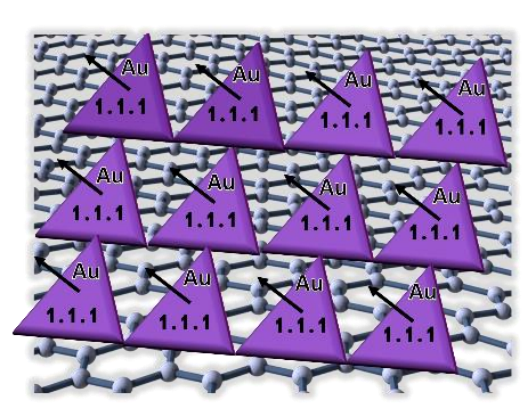

Ana Primo, ${ }^{[a]}$ Ivan Esteve-Adell, ${ }^{[a]}$ Simona N. Coman, ${ }^{[b]}$ Natalia Candu, ${ }^{[b]}$ Vasile I. Parvulescu ${ }^{[b]}$ and Hermenegildo Garcia $^{*[a]}$

Page No. - Page No.

One Step Pyrolysis Preparation of Oriented 1.1.1 Gold Nanoplatelets Supported on Graphene and Six Orders of Magnitude Enhancement of the Resulting Catalytic Activity. 